\title{
Природопользование
}

\section{Information about authors}

Matveeva Antonina Sergeevna - post-graduate student of Forestry Department, Federal State Educational Institution of Higher Education «Saint-Petersburg State Forest Technical University named after S.M. Kirov», SaintPetersburg, Russian Federation; e-mail: petkina92@mail.ru

Beliaeva Nataliia Valerievna - Professor of Forestry Department o Federal State Educational Institution of Higher Education «Saint-Petersburg State Forest Technical University named after S.M. Kirov», Dr. (Forestry), Professor of Forestry Department, Saint-Petersburg, Russian Federation; e-mail: galbe106@mail.ru

Danilov Dmitry Aleksandrovich - Director of Federal State Educational Scientific Institution «Leningrad Scientific Research Institute of Agriculture «Belogorka», $\mathrm{PhD}$ in Agriculture, Leningrad region, Russian Federation; e-mail: stown200@mail.ru

DOI: $10.12737 /$ article_59c22665a8ff90.84531444

УДК $630 * 181.1$

\section{ВЛИЯНИЕ МЕТЕОФАКТОРОВ НА РАДИАЛЬНЫЙ ПРИРОСТ КУЛЬТУР ДУБА ЧЕРЕШЧАТОГО В ПРАВОБЕРЕЖНОМ ЛЕСНИЧЕСТВЕ УОЛ ВГЛТУ ИМЕНИ Г.Ф. МОРОЗОВА}

\author{
А.И. Миленин ${ }^{1}$
}

1 - ФГБОУ ВО «Воронежский государственный лесотехнический университет имени Г.Ф. Морозова»,

г. Воронеж, Российская Федерация

Выявление связей между приростом деревьев и метеорологическими элементами имеет большое значение для понимания биологических процессов, оценки экологических факторов, определяющих рост и продуктивность лесных сообществ, прогнозирования прироста в связи с изменяющимися климатическими условиями. Дендроклиматический анализ может быть использован при планировании и осуществлении многочисленных лесохозяйственных мероприятий. В работе представлены данные по влиянию метеорологических факторов на радиальный прирост дуба черешчатого в лесотипологических культурах происхождением из снытевой дубравы позднораспускающейся разновидности. Дендрохронологический анализ радиального прироста проводился в соответствии с существующими методическими разработками. В динамике радиального прироста деревьев дуба черешчатого наблюдается цикличность. Наиболее отчетливо выделяются 2-3-, 5-7-, 11-, 22-летние циклы. Депрессии прироста главным образом обусловлены летними засухами с температурой воздуха выше среднегодовой нормы и количеством осадков меньше среднегодовой нормы. Периоды с повышенным радиальным приростом приходятся на годы с невысокой температурой воздуха и количеством осадков больше среднегодовой нормы. По степени влияния на радиальный прирост дуба черешчатого метеорологические элементы располагаются в следующем порядке: гидрометрический коэффициент; осадки осенне-зимние, летние, годовые; температура воздуха за вегетационный период активной вегетации (апрель-май), летняя, среднегодовая. Данные о влиянии метеорологических элементов подтверждаются результатами дисперсионного анализа. Наибольший показатель силы влияния с гидротермическим коэффициентом (ГТК) - 0,39, с осадками теплого периода - 0,32, суммой осадков за год - 0,30, наименьшее влияние с температурой воздуха - 0,20. Между температурой воздуха и приростом в теплый период существует обратная связь: повышение температуры воздуха способствует снижению прироста. Как избыток атмосферных осадков, так и недостаток способствуют снижению радиального прироста.

Ключевые слова: радиальный прирост, относительный индекс, дисперсионный анализ, показатель силы влияния, ширина годичного кольца. 
THE INFLUENCE OF METEOROLOGICAL FACTORS ON THE RADIAL GROWTH OF ENGLISH CULTURES IN THE RIGHT BANK FORESTRY OF EEF OF VSUFT NAMED AFTER G. F. MOROZOV

\author{
A.I. Milenin ${ }^{1}$ \\ 1 - FSBEI HE «Voronezh State University of Forestry and Technologies named after G.F. Morozov» Voronezh, \\ Russian Federation
}

\begin{abstract}
Exploring linkages between trees increment and meteorological elements is of great importance for understanding biological processes, assess of environmental determinants, defining growth and productivity of forest communities, forecasting growth in connection with changing climatic conditions. Dendroclimatic analysis can be used in planning and implementation of many forestry activities. The paper presents data on the effect of meteorological factors on the radial increment of English oak in isotopologues cultures originating from glague oak forest of serotinous variety. Dendrochronological analysis of radial growth was carried out in accordance with existing methodological developments. In the dynamics of radial growth of trees of English oak, periodicity is observed. 2-3-, 5-7-, 11-, 22-year cycles are seen more clearly. Growth depression is mainly due to the summer droughts with temperatures above average standards and rainfall less than average annual norms. Periods with high radial growth occur in years with high air temperatures and rainfall more than average standards. In terms of impact on the radial increment of English oak meteorological elements are arranged in the following order: hydrometric ratio; precipitation - autumn-winter, summer, annual; air temperature in the vegetation period of active growing season (April, May), summer, annual. Data on the influence of meteorological elements are confirmed by the results of analysis of variance. The highest power of the influence of the hydrothermal coefficient (HTC) is 0.39 , with precipitation of the warm period of is, the sum of precipitation for the year of is, the lowest effect with temperature is 0.20 . Between the air temperature and increment in the warm period there is an inverse relationship: the increase in air temperature reduces growth. Both excess of precipitation and the shortage contribute to the reduction of radial growth.
\end{abstract}

Keywords: radial growth, relative index, analysis of variance, index of power of influence, width of annual rings.

Актуальность. Для сохранения ценных лесных ресурсов необходимы знания не только об их современном состоянии, но и об изменениях, которые происходили за более длительный период. В связи с этим возрастающую актуальность приобретают дендрохронологические исследования $[2,5,6]$, которые могут быть использованы для прогнозирования прироста в связи с изменением климата [5-11]. Особенности прироста дуба черешчатого в зависимости от влияния различных метеорологических элементов изучали многие исследователи (Костин, 1968; Eфuмов, 1974 и др.) [3, 4]. Однако следует отметить, что не всегда учитывались особенности прироста в различных лесорастительных условиях и у разных внутривидовых категорий дуба черешчатого: экотипов, эдафотипов, фенологических разновидностей. Ряд работ, посвященных этому вопросу, выполнен на основании данных, полученных за небольшой проме- жуток времени (20-30 лет), при этом не всегда исключалось влияние возраста и происхождения [10-12].

Объекты и методика. Наши исследования были направлены на изучение многолетней динамики радиального прироста в оптимальных условиях произрастания свежей снытевой дубравы (ТЛУ-Д2), в насаждении позднораспускающейся разновидности дуба черешчатого искусственного происхождения. Культуры дуба черешчатого в Правобережном лесничестве УОЛ ВГЛТУ были созданы в 1953 году на площади 1,5 га. Желуди дуба были собраны в Теллермановской дубраве в аналогичном типе леса дубняк снытевый [1]. Длительное время за культурами проводили наблюдения, опубликованы работы по их росту и состоянию. За культурами регулярно проводился уход, убирались только мертвые деревья. Последний уход с удалением сухостойных деревьев проведен в 2015 г. В 2015 году сделан повторный перечет и взяты керны для анализа радиального прироста. 


\section{Природопользование}

Таксационная характеристика насаждений приведена в табл. 1. Древостой простой формы с преобладанием дуба 94 \% от общего запаса. Бонитет - I. Средняя высота насаждения - 23.0 м, средний диаметр - 24.0 см, полнота - 0.76. Запас $-241.1 \mathrm{~m}^{3} /$ га. Происхождение - искусственное семенное. Древостой дуба черешчатого состоит из позднораспускающейся разновидности. Подлесок - 5 Кл. т 2 Кл. п 2Бер. $б 1$ Лщ. Подрост - 7 Кл. о ЗЛп + Яс ед Д.
Напочвенный покров: $\mathrm{Cop}^{3}$ - сныть обыкновенная, $\mathrm{Cop}^{1}$ - осока волосистая, $\mathrm{Sp}$ - копытень европейский, Un - купена лекарственная. Рельеф ровный. Почва серая, лесная. Тип леса - Дсн. Тип лесорастительных условий - Д2.

Средний балл категории состояния определялся по количеству стволов - 1.47 и по запасу 1.3 и свидетельствует об удовлетворительном состоянии культур.

Таблица 1

Таксационная характеристика древостоя

\begin{tabular}{|c|c|c|c|c|c|c|c|c|}
\hline $\begin{array}{c}\text { Происхождение } \\
\text { желудей } \\
\text { ТЛ }\end{array}$ & $\begin{array}{c}\text { Возраст / } \\
\text { бонитет }\end{array}$ & Состав & $\begin{array}{c}\text { Д ср, } \\
\mathrm{cm}\end{array}$ & $\begin{array}{c}\mathrm{H} \mathrm{cp}, \\
\text { м }\end{array}$ & $\begin{array}{c}\text { Число } \\
\text { стволов } \\
\text { шт. на } \\
\text { га }\end{array}$ & $\begin{array}{c}\text { Сумма } \\
\text { Площадей } \\
\text { сечений } \\
\text { м²/га }\end{array}$ & Полнота & $\begin{array}{l}\text { Запас } \\
\mathrm{m}^{3} / \text { га }\end{array}$ \\
\hline $\begin{array}{c}\text { Дсн } \\
\text { поздний }\end{array}$ & $\frac{63}{\mathrm{I}}$ & $\begin{array}{l}\text { 94Д } \\
\text { 4Лп } \\
1 \text { Кл.о } \\
0.5 \text { Кл.т } \\
0.5 \text { Кл.о }\end{array}$ & $\begin{array}{l}24.0 \\
13.2 \\
10.7 \\
11.6 \\
11.6\end{array}$ & $\begin{array}{l}23.0 \\
12.4 \\
8.8 \\
9.2 \\
9.2\end{array}$ & $\begin{array}{l}452 \\
116 \\
44 \\
20 \\
28\end{array}$ & $\begin{array}{l}20.4 \\
1.59 \\
0.40 \\
0.21 \\
0.30\end{array}$ & $\begin{array}{l}0.65 \\
0.06 \\
0.02 \\
0.01 \\
0.02\end{array}$ & $\begin{array}{l}227.0 \\
9.3 \\
2.0 \\
1.16 \\
1.64\end{array}$ \\
\hline Итого (на га) & & & & & 660 & 22.9 & 0.76 & 241,1 \\
\hline
\end{tabular}

\section{Индексы радиального прироста, \% и количество осадков за IV-X месяц, мм ЛтП ДСН}

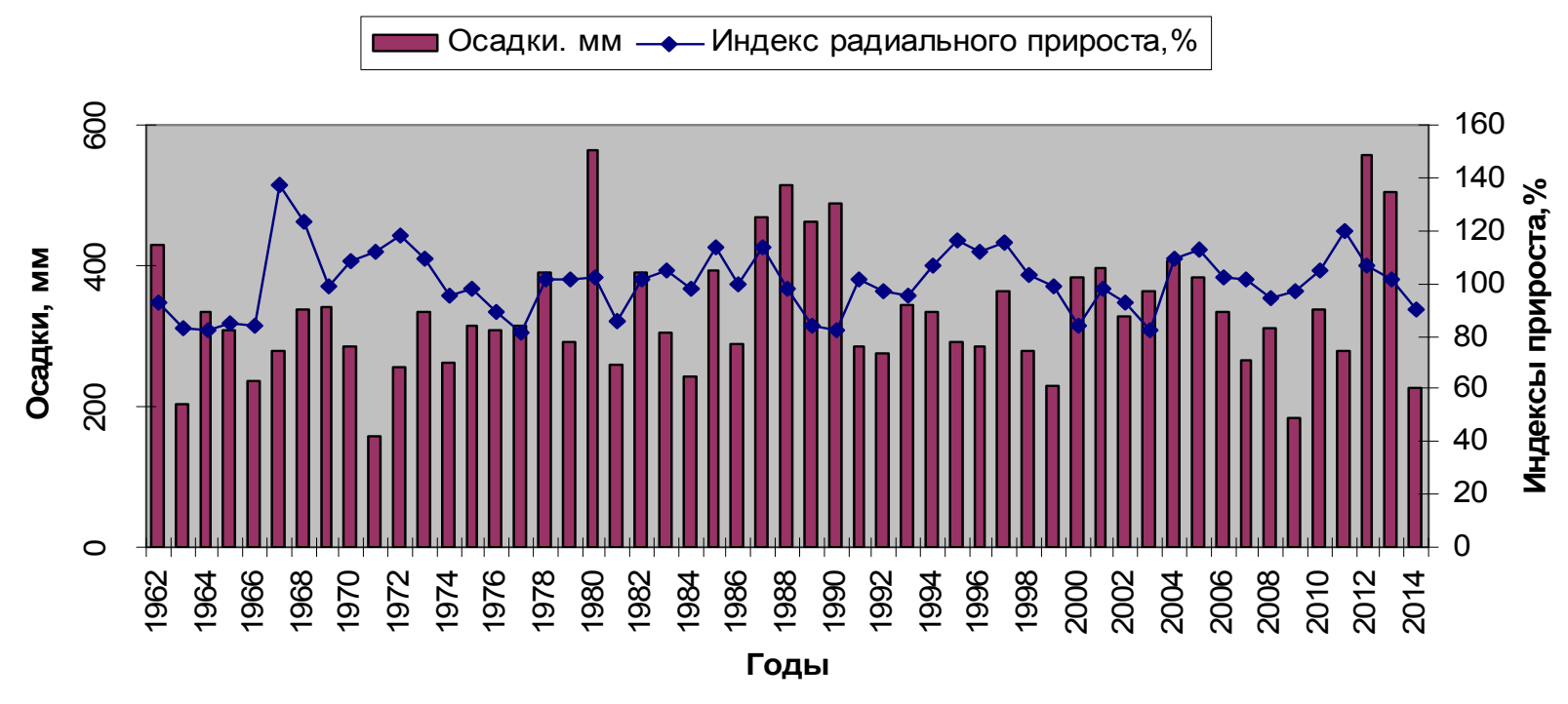

Рис. 1. Индекс ширины годичного кольца и количества выпавших осадков с апреля по октябрь, лесотипологическое происхождение желудей (ЛТП) из свежей снытьевой дубравы (Дсн) 
Дендрохронологический анализ радиального прироста проводился в соответствии с существующими методическими разработками [2]. Керны брали на пробной площади. Измерения ширины годичных колец проводили с помощью микроскопа МБС-1 с точностью до \pm 0.05 мм.

Среднюю ширину годичных колец определяли по формуле

$$
a_{i}=1 / n \sum_{j=1}^{n} x_{i} * \gamma,
$$

где $\mathrm{a}_{\mathrm{i}}$ - средние значение ширины годичных колец всех модельных деревьев і-го года;

n - число модельных деревьев;

$\mathrm{x}_{\mathrm{i}} * \gamma-$ ширина годичного кольца ј-го дерева, і-года.

С целью исключения влияния возраста проводили сглаживание исходных данных. Для учёта факторов, зависящих от индивидуальных особенностей деревьев или конкретных условий местопроизрастания применялся метод относительных индексов.

Показатель силы влияния рассчитывался как отношение факториальной суммы квадратов $\left(D_{x}\right)$ к общей сумме квадратов $\left(D_{y}\right)$ дисперсионного комплекса по формуле [7, 15]

$$
{ }^{\eta} \mathbf{x}^{2}=\mathrm{D}_{\mathrm{x} /} \mathrm{D}_{\mathrm{y}}
$$

В качестве результативного признака использовали относительные индексы, в качестве градаций факторов - суммы среднемесячных температур и осадков. Для оценки влияния температуры воздуха и осадков на радиальный прирост дуба черешчатого полученные данные были обработаны методом дисперсионного анализа и рассчитаны показатели силы влияния.

Данные об изменении основных метеорологических величин за период с 1953 по 2016 годы были взяты на метеостанции Воронежского агроуниверситета.
Результаты исследований. В динамике радиального прироста деревьев дуба черешчатого наблюдается цикличность. Наиболее отчетливо выделяются 2-3-, 5-7-, 11-, 22-летние циклы. Значительное снижение общего прироста наблюдается в 1962, 1971, 1972, 1983, 1985,1999, 2010 годах.

Повышенные значения индекса радиального прироста приходятся на следующие годы: 1961, 1978, 1992, 2006. Депрессии прироста главным образом обусловлены летними засухами с температурой воздуха выше среднегодовой нормы и количеством осадков меньше среднегодовой нормы. В математическом виде зависимость между приростом и температурой воздуха была установлена с использованием программы Aproks и выражается в виде нелинейного уравнения, из которого следует, что снижение радиального прироста происходит по мере увеличения средней температуры воздуха в 1972, 1984, 1990, 2001, 2010 гг.

Периоды с повышенным радиальным приростом приходятся на годы с невысокой температурой воздуха и количеством осадков больше среднегодовой нормы - 1969, 1986, 1997, 2006 годы (рис. 1). Такая же закономерность наблюдается и в насаждениях естественного происхождения, произрастающих в аналогичных типах леса $[7,8]$. Влияние летней температуры на радиальный прирост подтверждается графическими и математическими методами, которые можно использовать для прогнозирования прироста в связи с изменением климата. Как показали исследования, радиальный прирост в свежей снытевой дубраве Правобережного лесничества УОЛ ВГЛТУ, так же как и в других типах леса, зависит не только от количества годовых осадков, но и от характера выпадения их по сезонам года [10-14]. 


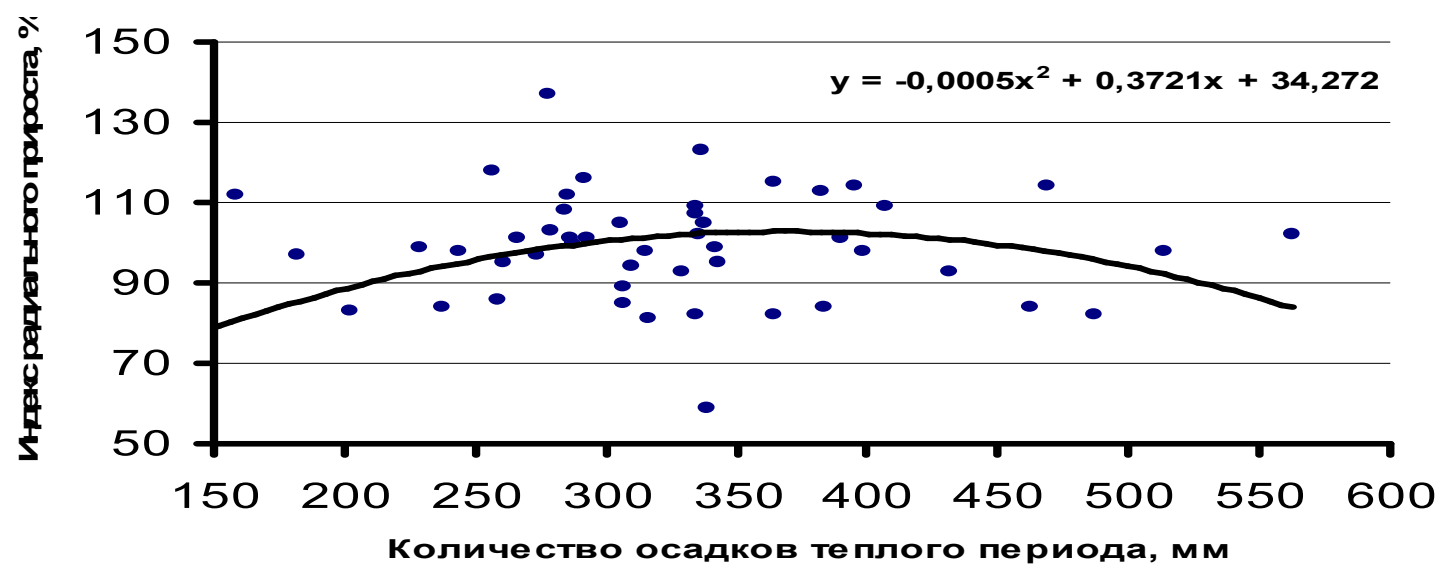

Рис. 2. Уравнение зависимости между индексом ширины годичного кольца и количеством выпавших осадков с апреля по октябрь

Большое значение имеют осадки зимнего периода, а также погодные условия в период начала активной вегетации в апреле - мае (рис. 2). Между среднесуточным количеством выпавших осадков в апреле и мае установлена наибольшая положительная связь, коэффициенты корреляции $+0,25$ и $+0,37$ соответственно. Связь между количеством осадков вегетационного периода (апрель, май) и радиальным приростом имеет нелинейный характер (рис. 3). Как избыток, так и недостаток осадков оказывает лимитирующее значение на радиальный прирост. Повышенные индексы радиального при- роста образуются в годы с количеством осадков вегетационного периода от 200 до 520 мм. По данным дисперсионного анализа фактический критерий Фишера $\left(\mathrm{F}_{\phi}\right)$ больше стандартного $\left(\mathrm{F}_{\mathrm{k}}\right)$, что также подтверждает влияние изученных метеорологических элементов на ширину годичного кольца. Наибольший показатель силы влияния с гидротермическим коэффициентом (ГТК) - 0,39, с осадками теплого периода - 0,32, суммой осадков за год - 0,30, наименьшее влияние с температурой воздуха $-0,20$ (табл. 2).

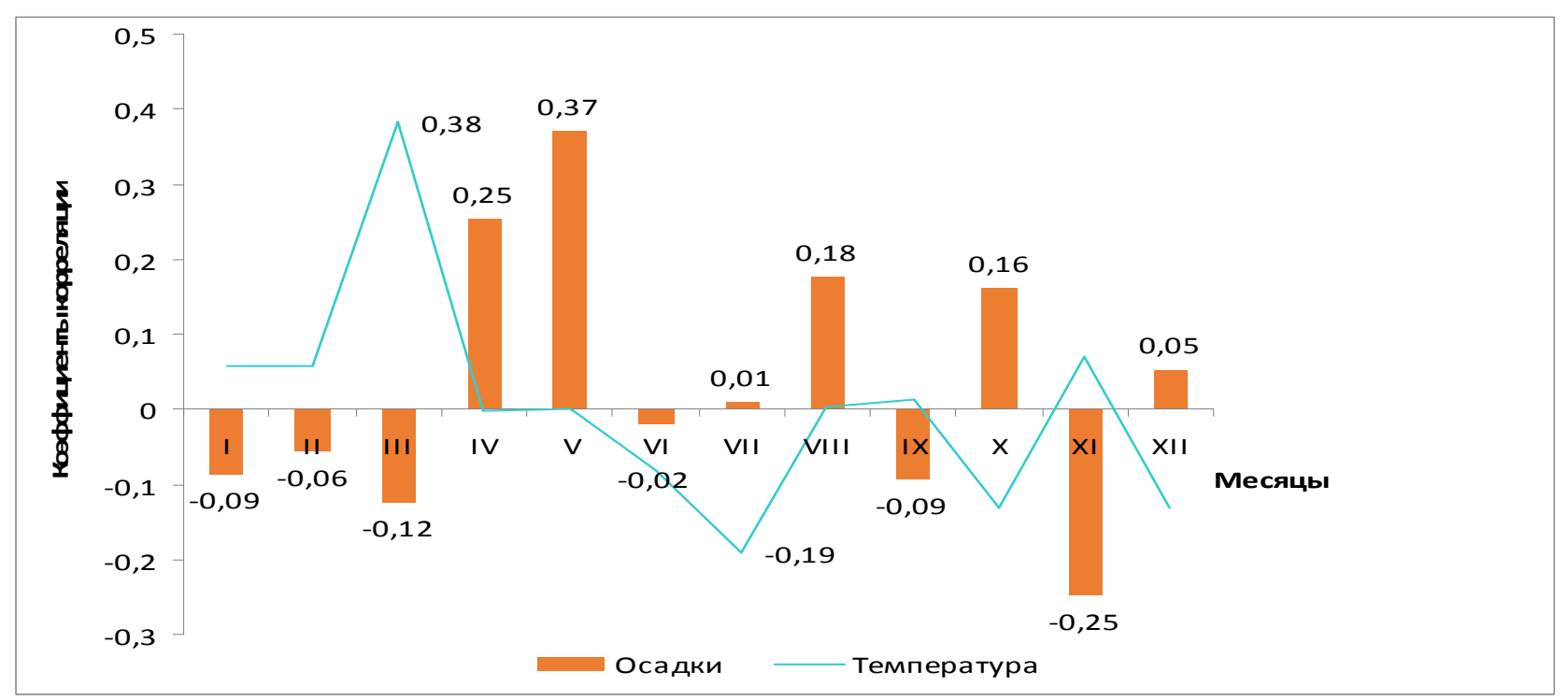

Рис. 3. Коэффициенты корреляции радиального прироста с осадками и температурой воздуха 


\section{Выводы:}

1. По степени влияния на радиальный прирост дуба черешчатого метеорологические элементы располагаются в следующем порядке: гидротермический коэффициент; осадки летние, осеннезимние, годовые; температура воздуха за вегетационный период активной вегетации (апрель-май), летняя, среднегодовая.
2. Между температурой воздуха и приростом в теплый период существует обратная связь: повышение температуры воздуха способствует снижению прироста.

3. Как избыток атмосферных осадков, так и недостаток способствуют снижению радиального прироста.

Таблица 2

Дисперсионный анализ влияния метеофакторов на радиальный прирост

\begin{tabular}{|l|c|c|c|c|}
\hline $\begin{array}{l}\text { Градации } \\
\text { фактора }\end{array}$ & $\begin{array}{l}\text { Факториальная диспер- } \\
\text { сия Д }\end{array}$ & $\begin{array}{l}\text { Показатель силы } \\
\text { влияния }\end{array}$ & \multicolumn{2}{|c|}{ Критерий Фишера } \\
\cline { 3 - 5 } ГТК & 0.1386 & 0.3856 & 1066.75 & 3.9 \\
\hline Температура & 1.3205 & 0.2012 & 947.47 & 3.9 \\
\hline $\begin{array}{l}\text { Осадки теплого } \\
\text { периода }\end{array}$ & 7789.8 & 0.3256 & 370.60 & 3.9 \\
\hline $\begin{array}{l}\text { Сумма } \\
\text { осадков за год }\end{array}$ & 10951.813 & 0.3021 & 1115.41 & 3.9 \\
\hline
\end{tabular}

\section{Библиографический список}

1. Ащеулов, Д.И. Состояние лесотипологических культур дуба черешчатого в Учебно-опытном лесхозе ВГЛТА [Текст] /: Проблемы деградации дубрав и современные системы ведения лесного хозяйства в них // Матер. научно-практ. семинара. Воронеж. 2007. С. 27-30.

2. Битвинскас, Т. Т. Дендроклиматические исследования. [Текст] / - Л.: Гидрометеоиздат., 1974. - 172 с.

3. Костин, С. И. Влияние осадков на прирост раннего и позднего дуба [Текст]/ Лесоведение - 1968. - № 2. - C. $80-83$.

4. Ефимов, Ю. П. Влияние осадков на прирост дуба черешчатого ранней $\quad$ и поздней форм в центральной лесостепи [Текст]/ Генетика, селекция и интродукция лесных пород. Воронеж. ЦНИИЛГиС, 1974. вып. 1. - С. 70 - 79.

5. Мелехов, И.С. Значение структуры годичных слоёв и её динамика в лесоводстве и дендроклиматологии [Текст]// Лесн. журнал.- 1979.- № 4.- С. 6-14.

6. Молчанов, А.А. Дендроклиматические основы прогнозов погоды [Текст].- М.: Наука, 1976.- 168 с.

7. Миленин, А.И. Влияние летних осадков на радиальный прирост дуба черешчатого в сухой снытьвоосоковой дубраве Шипова леса [Текст] // «Лесотехнический журнал». 2011. № 4-С. 72-75

8. Миленин, А.И. Влияние температуры воздуха на радиальный прирост дуба черешчатого в Шиповом лесу «Лесотехнический журнал». [Текст] // 2012. № 2-С. 65-69

9. Matveev S.M. Climatic Changes in the East-European Forest-Steppe and Effects on Scots Pine Productivity / S.M. Matveev, Yu.G. Chendev, A.R. Lupo, J.A. Hubbart, D.A. Timashchuk // Pure and Applied Geophysics. - 2016. DOI 10.1007/s00024-016-1420-y.

10. Matskovsky V. Dendroclimatology and historical climatology of Voronezh region, European Russia, since 1790s / V. Matskovsky, E. Dolgova, N. Lomakin, S. Matveev // Int. J. Climatol. - 2016. DOI: 10.1002/joc.4896.

11. Rozas V. Detecting the impact of climate and disturbances jn tree-rings of fagus sylvatika L. and quercus robur L. in a lowland Forest in Cantadria, Northern Spain. Annals of Forest Science. 2001. T. 58. № 3. C. $237-251$. 


\section{Природопользование}

\section{References}

1. Asheulov D.I. . Sostoyaniye lesotipologicheskikh kul'tur duba chereshchatogo v Uchebno-opytnom leskhoze VGLTA [State of forest typological cultures of oak tree in the educational-experimental leshoz VGLTA] /: Problemy degradatsii dubrav i sovremennyye sistemy vedeniya lesnogo khozyaystva $v$ nikh [Problems of degradation of oak forests and modern systems of forest management in them] // Mater. nauchno-prakt. seminara. Voronezh. [Mater. Scientific-practical. Seminar. Voronezh]. 2007. P. 27-30. (In Russian).

2. Bitvinsky T. T. Dendroklimaticheskiye issledovaniya [Dendroclimatic studies] / Gidrometeo-izdan. - [Moscow: Hydrometeo-issued.], 1974. - 172 p. (In Russian)..

3. Kostin S. I. Vliyaniye osadkov na prirost rannego i pozdnego duba [Effect of precipitation on the increment of early and late oak]. Leso-vedeniye[Forest-management]. - 1968. - no. 2. - pp. 80 - 83. (In Russian).

4. Efimov Yu. P. Vliyaniye osadkov na prirost duba chereshchatogo ranney i pozdney form v tsentral'noy lesostepi [Influence of precipitation on growth of pedunculate oak in early and late forms in the Central forest-steppe zone]. Genetika, selektsiya i introduktsiya lesnykh po-rod. Voronezh. TSNIILGiS [Genetics, selection and introduction of forest's family. Voronezh. Nilges], 1974. vol. 1. - pp. 70 - 79. (In Russian).

5. Melekhov I. S. Znacheniye struktury godichnykh sloyov i yeyo dinamika v lesovodstve $i$ dendroklimatologi [the importance of the structure of the annual layers and dynamics in forestry and dendroclimatology] Lesn. zhurnal [Lesn. journal].- 1979.- no. 4.- pp. 6-14. (In Russian).

6. Molchanov A. A. Dendroklimaticheskiye osnovy prognozov pogody [Dendroclimatic basis of weather forecasts] M.: Nau-ka,[- M.: Nauka], 1976.- 168 p. (In Russian).

7. Milenin A. I. Vliyaniye letnikh osadkov na radial'nyy prirost duba chereshchatogo $v$ sukhoy snyt'vo-osokovoy dubrave Shipova lesa [Influence of summer precipitation on the radial increment of pedunculate oak in dry snitovosedge oak Shipov forest]. «Lesotekhnicheskiy zhurnal». ["Forestry engineering journal"]. 2011. no. 4-pp. 72-75. (In Russian).

8. Milenin A. I. Vliyaniye temperatury vozdukha na radial'nyy prirost duba cheresh-chatogo v Shipovom lesu [Influence of air temperature on the radial increment of pedunculate oak in Finger-the woods] «Lesotekhnicheskiy zhurnal». ["Forestry engineering journal"]. 2012. no. 2-pp. 65-69. (In Russian).

9. Matveev S.M. Climatic Changes in the East-European Forest-Steppe and Effects on Scots Pine Productivity / S.M. Matveev, Yu.G. Chendev, A.R. Lupo, J.A. Hubbart, D.A. Timashchuk // Pure and Applied Geophysics. - 2016. DOI 10.1007/s00024-016-1420-y.

10. Matskovsky V. Dendroclimatology and historical climatology of Voronezh region, European Russia, since 1790s / V. Matskovsky, E. Dolgova, N. Lomakin, S. Matveev // Int. J. Climatol. - 2016. DOI: 10.1002/joc.4896.

11. Rozas V. Detecting the impact of climate and disturbances jn tree-rings of fagus sylvatika L. and quercus robur L. in a lowland Forest in Cantadria, Northern Spain. Annals of Forest Science. 2001. T. 58. № 3. C. $237-251$.

\section{Сведения об авторах}

Миленин Андрей Иванович - доцент кафедры лесоводства, лесной таксации и лесоустройства ФГБОУ ВО «Воронежский государственный лесотехнический университет имени Г.Ф. Морозова», кандидат сельскохозяйственных наук, г. Воронеж, Российская Федерация; e-mail: milenin2011@mail.ru

\section{Information about authors}

Milenin Andrey Ivanovich - Associate Professor of forestry of a forest taxation and forest facilities of FSBEI HE "Voronezh state forestry university named after G.F. Morozov", Candidate of Agricultural Sciences, Voronezh, Russian Federation; e-mail: milenin2011@mail.ru 